\title{
Residual cholesterol synthesis and simvastatin induction of cholesterol synthesis in Smith-Lemli-Opitz syndrome fibroblasts
}

\author{
Christopher A. Wassif ${ }^{\mathrm{a}}$, Patrycja A. Krakowiak ${ }^{\mathrm{a}, 1}$, Brooke S. Wright ${ }^{\mathrm{a}}$, \\ Jennifer S. Gewandter ${ }^{\mathrm{a}}$, Allison L. Sterner ${ }^{\mathrm{a}}$, Norman Javitt ${ }^{\mathrm{b}}$, Alfred L. Yergey ${ }^{\mathrm{c}}$, \\ Forbes D. Porter ${ }^{\mathrm{a}, *}$ \\ ${ }^{\text {a } H e r i t a b l e ~ D i s o r d e r s ~ B r a n c h, ~ N a t i o n a l ~ I n s t i t u t e ~ o f ~ C h i l d ~ H e a l t h ~ a n d ~ H u m a n ~ D e v e l o p m e n t, ~ N a t i o n a l ~ I n s t i t u t e s ~ o f ~ H e a l t h, ~ B e t h e s d a, ~ M D, ~ U S A ~}$ \\ ${ }^{\mathrm{b}}$ New York University Medical Center, New York, NY, USA \\ ${ }^{\mathrm{c}}$ Laboratory of Cellular and Molecular Biophysics, National Institute of Child Health and Human Development, National Institutes of Health, \\ Bethesda, MD, USA
}

Received 15 November 2004; received in revised form 21 December 2004; accepted 22 December 2004

Available online 5 February 2005

\begin{abstract}
Smith-Lemli-Opitz syndrome (RSH/SLOS) is an autosomal recessive, malformation syndrome caused by mutations in the $3 \beta-$ hydroxysterol $\Delta^{7}$-reductase gene ( $\left.D H C R 7\right)$. DHCR 7 catalyzes the reduction of 7-dehydrocholesterol (7DHC) to cholesterol. We report the mutation analysis and determination of residual cholesterol synthesis in 47 SLOS patients, and the effects of treatment of SLOS skin fibroblasts with simvastatin. Using deuterium labeling we have quantified the amount of synthesized cholesterol and 7DHC in homozygote, heterozygote, and control fibroblast cell lines. In SLOS fibroblasts, the fraction of synthesized cholesterol to total sterol synthesis ranged from undetectable to over 50\%. This establishes that different mutant alleles encode enzymes with varying degrees of residual activity. There was a correlation between increased phenotypic severity and decreased residual cholesterol synthesis $\left(r^{2}=0.45\right.$, $p<0.0001)$. Simvastatin treatment of SLOS fibroblasts with residual DHCR7 enzymatic activity decreased 7DHC levels and increased cholesterol synthesis. This increase in cholesterol synthesis is due to increased expression of a mutant allele with residual function. Determination of residual enzymatic activity for specific $D H C R 7$ mutant alleles will help in understanding the processes underlying the broad phenotypic spectrum found in this disorder and will be useful in identifying patients who may benefit from simvastatin therapy.

Published by Elsevier Inc.
\end{abstract}

Keywords: Smith-Lemli-Opitz syndrome; SLOS; 7-Dehydrocholesterol reductase; DHCR7; Cholesterol synthesis; Simvastatin

\section{Introduction}

Smith-Lemli-Opitz syndrome (SLOS) is a malformation syndrome due to mutations of the $3 \beta$-hydroxysterol $\Delta^{7}$-reductase gene (DHCR7). DHCR7 (EC 1.3.1.21) reduces 7-dehydrocholesterol (7DHC) to cholesterol in the last step of cholesterol biosynthesis. SLOS was first recognized as an inborn error of cholesterol synthesis

\footnotetext{
${ }^{*}$ Corresponding author. Fax: +1 3014805791.

E-mail address: fdporter@mail.nih.gov (F.D. Porter).

${ }^{1}$ Present address: University of Arkansas for Medical Sciences, Little Rock, AR, USA.
}

in 1993 by Irons et al. [1,2]. In 1998, DHCR7 was cloned and the first mutations of $D H C R 7$ were identified in SLOS patients [3-6]. Currently over 100 different mutations of DHCR7 have been reported in SLOS patients [7]. The estimated clinical incidence of this disorder in populations of northern and central European heritage is $1 / 25,000-1 / 60,000$ [8-10]. The SLOS phenotypic spectrum is extremely variable; however, typical manifestations include growth failure, microcephaly, cleft palate, heart malformations, colonic aganglionosis, hypospadias or ambiguous genitalia, limb anomalies including syndactyly of the second and third toes, mental retardation, and autism [11-14]. 
Phenotypic severity in SLOS patients can vary significantly among patients with the same genotype $[12,15]$. This variability suggests that factors other than genotype significantly influence phenotypic expressivity of this disorder. These epigenetic factors could include maternal factors [16], altered expression of different alleles, modifier genes that influence cholesterol homeostasis, modifier genes that influence phenotypic expression, or variable residual enzymatic activity. For many inborn errors of metabolism, residual enzymatic activity often significantly influences severity. To date, a systematic evaluation of residual cholesterol synthesis in SLOS has not been performed.

Measurement of cholesterol synthesis in cell lines is confounded by the large amounts of preexisting cholesterol in cells prior to induction of cholesterol biosynthesis. Due to the slow turnover of cholesterol, this preexisting cholesterol persists even after cholesterol synthesis is induced in growing fibroblasts. Deuterium oxide has been used to measure fractional cholesterol synthesis both in vitro and in vivo [17-22]. One advantage of deuterium labeling is that it is non-radioactive. Thus, this method will be applicable to future in vivo studies.

Current therapy of SLOS consists of dietary cholesterol supplementation. Observational studies suggest that dietary cholesterol supplementation is beneficial [23-27]; however, dietary cholesterol supplementation has three major limitations. First, significant amounts of cholesterol do not appear to cross the blood-brain barrier [28-32]. Second, the clinical efficacy of dietary cholesterol supplementation is limited by fixed developmental problems. Third, 7DHC levels are not completely suppressed; therefore, potential toxic effects of 7DHC persist. 7DHC, or a metabolite of 7DHC, appears to inhibit normal intracellular metabolism of LDL derived cholesterol [33] and increases the degradation of HMG-CoA reductase [34]. 7DHC can be incorporated into biologically active aberrant oxysterols [35], can lead to aberrant bile acid synthesis [36,37], and enter the steroid biosynthetic pathway [38]. The biological consequences of these abnormal sterol metabolites have not yet been elucidated. The use of HMG-CoA reductase inhibitors to reduce 7DHC levels in SLOS has also been proposed and tested in two small trials with divergent outcomes [39-41].

This report presents genotypic analysis and residual enzyme activity determination in fibroblasts from 47 SLOS patients, 4 DHCR7 heterozygotes, and 3 controls. The correlations between measured residual cholesterol synthesis, clinical severity, diagnostic sterol levels, and genotype are analyzed. We also show that simvastatin induces $D H C R 7$ mRNA expression and can increase fractional cholesterol synthesis in SLOS fibroblasts. Determination of residual DHCR7 enzymatic activity will be useful for selecting patients who may have a beneficial response to simvastatin therapy.

\section{Materials and methods}

\section{Subjects}

This study was approved by the National Institute of Child Health and Human Development Institutional Review Board and informed consent was obtained. Clinical diagnosis of SLOS was confirmed in all patients by biochemical testing. Severity scores presented in this report were generated as previously described [11,42]. Using severity scores, patients were categorized as mild $(<20)$, typical $(20-35)$, or severe $(>35)$. These groupings accurately reflected the clinical status of most SLOS patients in this cohort.

\section{Mutational analysis}

Mutation analysis was performed as previously described [43,44]. DNA (Puregene kit, Gentra, Minneapolis, MN) and RNA (RNeasy kit, Qiagen, Valencia, CA) were isolated from blood and skin fibroblasts as per the manufacturer's protocols. Sequencing was performed on a Beckman-Coulter CEQ2000 automated sequencer using Beckman-Coulter reagents (Fullerton, CA).

\section{Cell culture}

SLOS skin fibroblasts were obtained from patients with SLOS confirmed by biochemical testing. Control cell lines were obtained from the National Institute of General Medical Sciences Human Genetic Mutant Cell Repository and the American Type Culture Collection. Sequencing of RT-PCR products from control cell lines established that they are homozygous wild type at the DHCR7 locus. Heterozygous cell lines were obtained from parents of several patients. Fibroblasts were propagated $\left(37^{\circ} \mathrm{C}, 5 \% \mathrm{CO}_{2}\right)$ in Dulbecco's modified Eagle's medium (DMEM, Invitrogen, Carlsbad, CA) supplemented with $10 \%$ fetal bovine serum (FBS, Gemini, Calabasas, CA). Cholesterol-deficient conditions were accomplished by growing cells in McCoy's 5A medium (Invitrogen) supplemented with 7.5\% lipoprotein-deficient serum (LPDS). LPDS was prepared as previously described [45] and cholesterol content was $153 \mathrm{ng} / \mathrm{ml}$. Growth in LPDS supplemented medium induces endogenous cholesterol synthesis. All medium were also supplemented with $0.29 \mathrm{mg} / \mathrm{ml}$ L-glutamine, $100 \mathrm{U} / \mathrm{ml}$ penicillin $\mathrm{G}$ sodium, and $100 \mathrm{mg} / \mathrm{ml}$ streptomycin sulfate (Invitrogen).

\section{Determination of cholesterol and 7DHC synthesis}

Sterol synthesis in fibroblasts was determined by using mass isotopomer distribution analysis to measure deuterium incorporation into cholesterol and 7DHC as follows. Fibroblasts were grown to confluence in T-75 
flasks in DMEM supplemented with 10\% FBS $(10 \%$ DMEM), and then plated in triplicate at a density of 350,000 cells in a T-25 flask with 10\% DMEM. After overnight growth, cell cultures were washed once with phosphate buffered saline (PBS, pH 7.4) containing $25 \% \mathrm{D}_{2} \mathrm{O}$ (99.9 at.\% D, Sigma-Aldrich, St. Louis, $\mathrm{MO})$. Medium was changed to McCoy's 5A medium supplemented with $7.5 \%$ LPDS and $25 \% \mathrm{D}_{2} \mathrm{O}$ (LPDS/ $\mathrm{D}_{2} \mathrm{O}$ ). After 5 days of culture in LPDS/ $/ \mathrm{D}_{2} \mathrm{O}$ medium, cell pellets were obtained by incubation in $3 \mathrm{ml}$ of $0.05 \%$ trypsin for $5 \mathrm{~min}$ at $37^{\circ} \mathrm{C}$, quenched with $6 \mathrm{ml}$ PBS $\left(25 \% \quad \mathrm{D}_{2} \mathrm{O}\right)$, and centrifuged for $3 \frac{1}{2} \mathrm{~min}$ at $3000 \mathrm{rpm}$. Cell pellets were washed once with PBS $\left(25 \% \mathrm{D}_{2} \mathrm{O}\right)$, frozen on dry ice, and stored at $-80{ }^{\circ} \mathrm{C}$ prior to analysis. An average cell count of the fibroblasts was obtained. Sample preparation was as described by Kelley [46], with minor modification. Two micrograms of $5 \beta$-cholestan-3 $\beta$-ol (coprostanol, Sigma) was added to each sample as a surrogate internal standard and cell pellets were saponified with $4 \%$ potassium hydroxide in ethanol for $1 \mathrm{~h}$ at $60^{\circ} \mathrm{C}$. The samples were then extracted with an equal volume of ethyl acetate and centrifuged for $5 \mathrm{~min}$ at $3000 \mathrm{rpm}$. The organic phase was removed and blown to dryness under a stream of nitrogen. Extracted sterols were derivatized with bis-trimethylsilytrifluoroacetamide (BSTFA) plus 1\% trimethylchlorosilane (TMCS) (Pierce Biotechnology, Rockford, IL) for $1 \mathrm{~h}$ at $60^{\circ} \mathrm{C}$.

Total cholesterol and 7DHC were determined as follows. The derivatized sterol preparation was injected on an Agilent 6890 gas chromatogram equipped with a flame ionization detector (GC/FID) and a ZB-1701 $30 \mathrm{~m} \times 0.32 \mathrm{~mm} \times 0.25 \mu \mathrm{m}$ column (Phenomenex, Torrance, CA). Initial oven temperature was $170^{\circ} \mathrm{C}$. For elution, the oven temperature was increased at a rate of $21^{\circ} \mathrm{C} / \mathrm{min}$ to $250^{\circ} \mathrm{C}$ and then increased at a rate of $3{ }^{\circ} \mathrm{C} / \mathrm{min}$ to $290{ }^{\circ} \mathrm{C}$. For cholesterol and 7DHC, typical retention times were 13.2 and $13.9 \mathrm{~min}$, respectively. Retention times were confirmed using standards for cholesterol and 7DHC (Sigma). Peak identification was based on retention time, comparison to the retention time of the internal coprostanol standard (typical retention time $11.6 \mathrm{~min}$ ), and comparison to an equivalent sample characterized by gas chromatography/mass spectroscopy (GC/MS).

After total cholesterol and 7DHC amounts were determined, samples were analyzed on a Finnigan Trace GC/MS using the same column and temperature elution profile described above. On this instrument, cholesterol and 7DHC had typical retention times of 14.7 and $15.4 \mathrm{~min}$, respectively (Fig. 1B). For these analyses, the mass spectrometer was tuned on cholesterol's $\mathrm{M}_{0}$ ion at $\mathrm{m} / \mathrm{z}$ 329. Detection parameters were adjusted until the natural distribution of the $\mathbf{M}_{+1}(\mathrm{~m} / \mathrm{z} 330)$ and the $\mathbf{M}_{+2}$ ion $(\mathrm{m} / \mathrm{z} 331)$ of cholesterol could be determined within a $3 \%$ error. Since ion mass increases by one pro- ton mass for each deuterium atom incorporated, the GC/MS was programmed to scan $\mathrm{m} / \mathrm{z} 324-340$ at $6 \mathrm{scans} / \mathrm{s}$. This mass range incorporated the entire isotopic envelope for both the $\mathrm{m} / \mathrm{z} 329$ ion of cholesterol and the $\mathrm{m} / \mathrm{z} 325$ ion of 7DHC (Figs. 1C and D). 8-Dehydrocholesterol (8-DHC) is an isomer of 7DHC found in vivo. Under our chromatographic conditions, 8DHC has a retention time similar to cholesterol. If $8 \mathrm{DHC}$ were present in the cholesterol peak, it would be recognized by the presence of an $\mathrm{m} / \mathrm{z} 325$ peak. The potential contribution of $8 \mathrm{DHC}$ to the cholesterol isotopic envelope could be recognized and accounted for. Neither 8DHC nor desmosterol were present in appreciable amounts in cultured fibroblasts (data not shown). A small peak of lathosterol could be detected in some cultures; however, its contribution to total sterols was negligible. Its retention time allowed for separation from both cholesterol and 7DHC. Detection limits and a standard curve were determined using D6-cholesterol (Cambridge).

The fraction of deuterium labeled cholesterol and 7DHC was determined by analyzing the entire nuclear envelope $\mathrm{M}_{0}-\mathrm{M}_{+9}$. For cholesterol and $7 \mathrm{DHC}$, these were $m / z \quad 329-338$ and $m / z \quad 325-334$, respectively. ${ }^{13} \mathrm{C}$ naturally occurs at $1.1 \%$ and thus contributes to the isotopic envelop. The contribution of naturally occurring ${ }^{13} \mathrm{C}\left(\sum\left(\mathrm{M}_{\mathrm{C} 1}+\mathrm{M}_{\mathrm{C} 2}+\mathrm{M}_{\mathrm{C} 3}\right)\right)$ to the observed signal $\left(\sum\left(\mathrm{M}_{0}+\mathrm{M}_{+1}+\mathrm{M}_{+2}+\mathrm{M}_{+3}+\mathrm{M}_{+4}+\mathrm{M}_{+5}+\mathrm{M}_{+6}+\right.\right.$ $\left.\mathbf{M}_{+7}+\mathbf{M}_{+8}+\mathbf{M}_{+9}\right)$ ) can be determined relative to the intensity of $\mathrm{M}_{0}$. The contribution to the observed relative ion intensities arising from naturally occurring ${ }^{13} \mathrm{C}$ was subtracted from the observed signal for $\mathrm{M}_{+1}$, $\mathbf{M}_{+2}$, and $\mathbf{M}_{+3}$. Beyond $\mathbf{M}_{+3}$, the contribution from the natural background was negligible. The natural abundance of deuterium is $0.015 \%$, thus its contribution is negligible. The corrected signal is determined by the equation: $\sum\left(\mathrm{M}_{\mathrm{D} 1}+\mathrm{M}_{\mathrm{D} 2}+\mathrm{M}_{\mathrm{D} 3}+\mathrm{M}_{\mathrm{D} 4}+\mathrm{M}_{\mathrm{D} 5}+\right.$ $\left.\mathrm{M}_{\mathrm{D} 6}+\mathrm{M}_{\mathrm{D} 7}+\mathrm{M}_{\mathrm{D} 8}+\mathrm{M}_{\mathrm{D} 9}\right)=\sum\left(\mathrm{M}_{+1}+\mathrm{M}_{+2}+\mathrm{M}_{+3}+\right.$ $\left.\mathrm{M}_{+4}+\mathrm{M}_{+5}+\mathrm{M}_{+6}+\mathrm{M}_{+7}+\mathrm{M}_{+8}+\mathrm{M}_{+9}\right)-\sum\left(\mathrm{M}_{\mathrm{C} 1}+\right.$ $\left.\mathrm{M}_{\mathrm{C} 2}+\mathrm{M}_{\mathrm{C} 3}\right)$. Once $\sum\left(\mathrm{M}_{\mathrm{D} 1}+\mathrm{M}_{\mathrm{D} 2}+\mathrm{M}_{\mathrm{D} 3}+\mathrm{M}_{\mathrm{D} 4}+\right.$ $\mathrm{M}_{\mathrm{D} 5}+\mathrm{M}_{\mathrm{D} 6}+\mathrm{M}_{\mathrm{D} 7}+\mathrm{M}_{\mathrm{D} 8}+\mathrm{M}_{\mathrm{D} 9}$ ) is determined, the fraction of total cholesterol present in the cell pellet which is deuterium labeled (newly synthesized) can be determined. The amount of deuterium labeled cholesterol was determined by the equation (corrected signal/ observed signal) multiplied by the amount of cholesterol determined by GC/FID analysis. The same method was used to determine the amount of newly synthesized 7DHC. Because we were interested in measuring both cholesterol and 7DHC we measured the entire isotopic envelope rather than measuring the excess mass of a specific ion [17]. Measuring the entire isotopic envelope avoids the need to make assumptions as to the number of hydrogen atoms in cholesterol or 7DHC derived from $\mathrm{H}_{2} \mathrm{O}$ or $\mathrm{D}_{2} \mathrm{O}$, assumptions as to the number and position and equivalency of exchangeable hydrogen atoms 

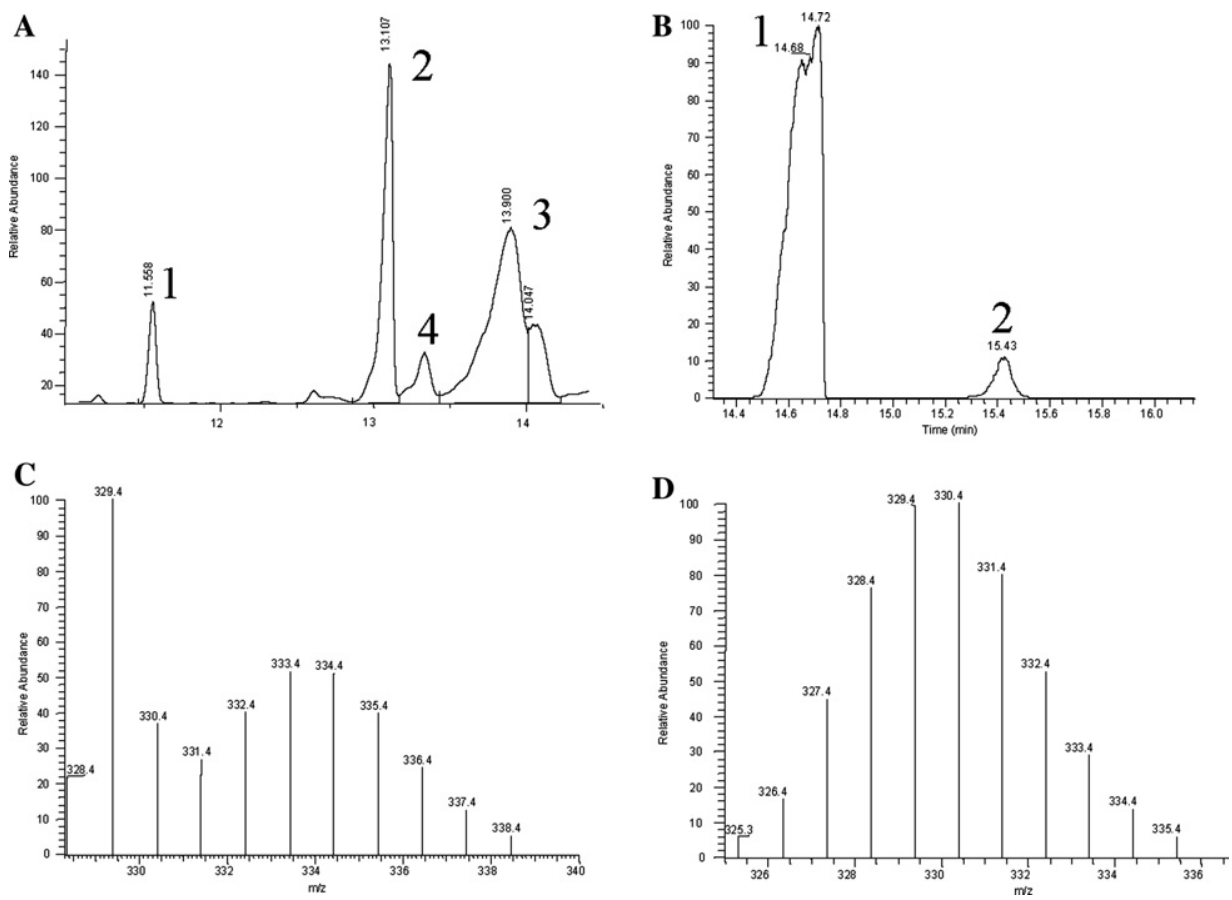

Fig. 1. Gas chromatographic analysis of deuterium labeled cholesterol and 7DHC. (A) Determination of total sterols by gas chromatography/flame ionization detection. This chromatogram is from an IVS8-1G $>$ C/IVS8-1G $>$ C cell line grown such that both preexisting and newly synthesized 7DHC were present. Two micrograms of coprostanol (peak 1) was added as an internal standard. Cholesterol (peak 2) and 7DHC (peak 3) mass was determined relative to coprostanol. Note the separation of the 7DHC peak in this figure represents earlier elution of deuterium labeled 7DHC. The entire 7DHC peak was analyzed to avoid introducing an error in our mass distribution analysis caused by the earlier elution of deuterium labeled molecules. A small peak of lathosterol (peak 4) was observed in some samples. (B) Gas chromatography/mass spectrometry of deuterium labeled cholesterol and 7DHC. The ion tracing for $m / z$ 324-340 is shown. Peak 1 is cholesterol and peak 2 is 7DHC. The dual peak of cholesterol is due to earlier elution of deuterium labeled ions. (C) The isotopic distribution of cholesterol derived ions from peak one shown in (B). The $\mathbf{M}_{0}$ ion is $m / z 329$. This peak represents unlabeled cholesterol. Deuterium labeled cholesterol ions form an isotopic envelope from $\mathrm{m} / \mathrm{z} 330-338$. Natural abundance of ${ }^{13} \mathrm{C}$ and ${ }^{2} \mathrm{H}$ contribute to the asymmetric nature of this isotopic envelope at $\mathrm{M}_{+1}$. (D) The isotopic distribution of 7DHC derived ions from peak 2 shown in (B). The $\mathrm{M}_{0}$ ion is $m / z$ 325. This peak represents unlabeled 7DHC. Growth conditions for this experiment were such that little preexisting 7DHC was present. Deuterium labeled 7DHC ions form an isotopic envelope that was measured from $\mathrm{m} / z$ 326-334.

in cholesterol or 7DHC, errors due to potential differences in isotope incorporation or fragmentation between cholesterol and 7DHC, and errors due to variation in $\mathrm{D}_{2} \mathrm{O}$ concentrations during incubation. The mass distribution was determined for the entire cholesterol and 7DHC elution peak in order to avoid introduction of an error in our mass distribution analysis caused by the earlier elution of deuterium labeled molecules. Using this method, we were able to detect 12.95 pmoles of cholesterol-D6 (Cambridge Isotope) diluted into 518.13 pmoles of cholesterol. All determinations were done in triplicate. Consistent values were obtained when individual cell lines were analyzed in separate experiments.

\section{Simvastatin treatment}

SLOS fibroblast cell lines were treated with simvastatin at concentrations ranging from 0.1 to $10 \mathrm{mcg} / \mathrm{ml}$ as described in the text and figure legends. Fibroblasts were grown to confluence in T-185 flasks in 10\% DMEM, and then plated at 650,000 cells in a T-75 flask and grown in
$10 \%$ DMEM for $24 \mathrm{~h}$. After $24 \mathrm{~h}$, the cells were washed with PBS and the media changed to LPDS/ $\mathrm{D}_{2} \mathrm{O}$ with or without simvastatin as noted in the figure legends. Cells were harvested after 3 days and fractional cholesterol synthesis was determined. To test the ability of simvastatin to decrease accumulated 7DHC, fibroblasts were first grown in LPDS for 3 days to allow for the accumulation of 7DHC. After 3 days, simvastatin $(1.0 \mathrm{mcg} / \mathrm{ml})$ was added to the cholesterol-deficient media, and cultures were grown for an additional 2 days. Sterol composition was analyzed as described above.

\section{Quantitative PCR}

RNA was isolated from cultured cells using a Qiagen RNeasy kit as per the manufacturer's protocol. Cell cultures were grown as described above except for the omission of $\mathrm{D}_{2} \mathrm{O}$. A cDNA archive was produced from $1 \mu \mathrm{g}$ RNA using the Applied Biosystems (Foster City, CA) high capacity cDNA archive kit. Transcript levels were then quantified using the $\Delta \Delta C_{\mathrm{t}}$ method on an ABI Prism 7000 with On Demand Probes. Standard $50 \mu 1$ reactions 
with $50 \mathrm{ng}$ cDNA, as per manufacturer's protocol, were performed. Validity of the $\Delta \Delta C_{\mathrm{t}}$ method, relative to GAPDH, was established for all probes. The probes used were DHCR7 (HS00154732), HMGCR (HS00168352), DHCR24 (HS00207388), SREBP2 (HS00190237), LDLR (HS00181192), FDFT (HS00189506), and NSDHL (HS00210873). All determinations were performed in triplicate.

\section{Results}

Clinical severity, diagnostic sterol levels, genotype, and de novo sterol synthesis of 47 SLOS patients, 4 heterozygous cell lines, and 3 control cell lines are presented in Table 1. Patients in this study had severity scores ranging from 6 to 80 . In this SLOS cohort, 22, 13, and 12 patients had a mild, classical or severe phenotype, respectively. Correlations between diagnostic plasma cholesterol levels as a fraction of total sterol levels and clinical severity have previously been reported [44,47]. For the patients in this study, we found a similar correlation between clinical severity scores and the fraction of cholesterol at diagnosis (Fig. 2A, $r^{2}=0.36, p<0.001$ ).

Consistent with previous series, the common splice acceptor mutation, IVS8-1G $>$ C, was found in 29 of the patients $(62 \%)$ and accounted for $32 \%(30 / 94)$ of the mutant alleles. The T93M $(278 \mathrm{C}>\mathrm{T})$ mutant allele was the second most frequent $D H C R 7$ mutation identified and accounted for $7.4 \%$ (7/94) of the mutant alleles. T93M was only identified in combination with a null allele (IVS8-1G $>\mathrm{C}$ or W151X). The R242C allele was identified in six patients (including one sib pair). Mutations not reported by other groups include Q98X, S113C, G138V, I145L, F235S, G344R, W248R, H405Y, H426P, and 1348delC. Clinical and molecular details of these mutations are being reported in detail elsewhere.

Residual cholesterol synthesis was measured in SLOS, heterozygous, and control fibroblasts by labeling newly synthesized sterols with deuterium. Total cholesterol and 7DHC amounts present in cell pellets were quantified by GC/FID in comparison to a known amount of coprostanol (Fig. 1A). During sterol synthesis, incorporation of an atom of deuterium from $\mathrm{D}_{2} \mathrm{O}$ rather than incorporation of an atom of hydrogen from $\mathrm{H}_{2} \mathrm{O}$ increases the molecular weight of either cholesterol or $7 \mathrm{DHC}$ by $1 \mathrm{amu}$. When skin fibroblasts were grown in medium containing $25 \% \mathrm{D}_{2} \mathrm{O}$, we observed an isotopic envelope of deuterium that corresponded to newly synthesized cholesterol (Figs. 1B and C) or 7DHC (Figs. $1 \mathrm{~B}$ and $\mathrm{D})$. The maximum relative abundance of deuterium labeled cholesterol and $7 \mathrm{DHC}$ occurred at $\mathrm{M}_{+4}$ and $\mathrm{M}_{+5}$.

Decreased fractional cholesterol synthesis correlated with increased clinical severity scores in this group of
SLOS patients (Fig. 2B, $r^{2}=0.45, p<0.0001$ ). The relationship between fractional cholesterol synthesis and clinical severity is well modeled by a Gaussian distribution (Fig. $2 \mathrm{~B}, r^{2}=0.73$ ). Fractional synthesis of cholesterol was significantly different (ANOVA for linear trend between columns, $p<0.0001$ ) when patients were grouped according to clinical severity (Fig. 2C). The relationship between diagnostic cholesterol fraction and fractional cholesterol synthesis is shown in Fig. $2 \mathrm{D}\left(r^{2}=0.27, p<0.0003\right)$.

Genotype-phenotype correlations in SLOS are complicated by the fact that most patients are compound heterozygotes and over 100 different mutations have been described. However, 10 genotypes are represented by two or more patients in this cohort. Two of the more common DHCR7 mutations, W151X and IVS8-1G >C, appear to be null alleles. The $1 \%$ fractional cholesterol synthesis measured in the IVS8-1G $>$ C/IVS8-1G $>C$ cell line probably reflects non-enzymatic hydrogen-deuterium exchange. Thus, in cell lines with either W151X or IVS8-1G $>\mathrm{C}$ alleles, residual DHCR7 enzymatic activity can be ascribed to the second allele. Seven subjects (clinical severity range: 11-33) had the T93M allele in combination with either W151X or IVS8-1G $>C$ (Fig. 2E). Mean fractional cholesterol synthesis was $0.24 \pm 0.06$ for this group (range 0.16-0.31). None of these patients were sibs. Fig. $2 \mathrm{~F}$ shows the residual activity present in seven other alleles found in association with the IVS8-1G $>\mathrm{C}$ allele for which more than one patient was available. Patients 18 and 19 are brothers. Fibroblasts from a brother and sister (patients 40 and 41) with R242C/R450L alleles were also studied and residual cholesterol synthesis was $0.24 \pm 0.04$ and $0.19 \pm 0.02$ for these two patients. In general, except for S169L (patients 12 and 13) and Y318N (patients 21 and 22), similar results were obtained for fibroblasts from patients with the same genotype. Of note, the fractional cholesterol synthesis determined for fibroblasts from patient 21 (IVS8-1G $>$ C/Y318) is lower than expected given this patient's phenotypic severity. This discrepancy may be an artifact due to a problem with this specific fibroblast line.

Witsch-Baumgartner et al. [44] classified DHCR7 mutations into four groups of increasing severity based on predicted protein structure: carboxy terminus (CT) $<$ transmembrane (TM) $<$ fourth cytoplasmic loop $(4 \mathrm{~L})<$ null $(0)$. Using this classification system, they showed that both clinical severity and the fraction of plasma 7DHC correlated with the type of DHCR7 mutation. Because this classification system correlated with both phenotypic and biochemical parameters, we analyzed fractional cholesterol synthesis with respect to these four mutation types. For this analysis, each patient was classified according to the least severe mutation type present. Although variation between column means is not significant (ANOVA, $p=0.09$ ) and a large 
Table 1

SLOS clinical phenotype and fractional cholesterol synthesis

\begin{tabular}{|c|c|c|c|c|c|c|c|}
\hline \multirow[t]{2}{*}{ Patient } & \multirow{2}{*}{$\begin{array}{l}\text { Severity } \\
\text { score }\end{array}$} & \multirow{2}{*}{$\begin{array}{l}\text { Severity } \\
\text { category }\end{array}$} & \multicolumn{3}{|c|}{ Diagnostic plasma sterol levels } & \multirow[t]{2}{*}{ Genotype } & \multirow{2}{*}{$\begin{array}{l}\text { Fractional cholesterol synthesis } \\
\text { Cholesterol/(cholesterol }+7 \mathrm{DHC})\end{array}$} \\
\hline & & & $\begin{array}{l}\text { Cholesterol } \\
(\mathrm{mg} / \mathrm{dl})\end{array}$ & $\begin{array}{l}\text { 7DHC } \\
(\mathrm{mg} / \mathrm{dl})\end{array}$ & $\begin{array}{l}\text { Cholesterol/ } \\
\text { (cholesterol + 7DHC) }\end{array}$ & & \\
\hline $1^{\mathrm{a}}$ & 80 & Severe & 7.6 & 5.2 & 0.59 & IVS8-1G $>C$ C/IVS8-1G $>C$ & 0.01 \\
\hline $2^{\mathrm{b}}$ & 11 & Mild & 73 & 6.2 & 0.92 & IVS8-1G $>$ C/T93M & 0.31 \\
\hline $3^{\mathrm{b}}$ & 22 & Mild & 43 & 16 & 0.73 & IVS8-1G $>C$ /T93M & 0.21 \\
\hline $4^{\mathrm{b}}$ & 33 & Classical & 33 & 5.4 & 0.86 & IVS8-1G $>C$ /T93M & 0.16 \\
\hline 5 & 28 & Classical & 25 & 23 & 0.52 & IVS8-1G $>C / T 93 M$ & 0.27 \\
\hline 6 & 33 & Classical & 51 & 7.6 & 0.87 & IVS8-1G >C/T93M & 0.26 \\
\hline $7^{\mathrm{b}}$ & 22 & Classical & 32 & 14 & 0.70 & W151X/T93M & 0.19 \\
\hline 8 & 22 & Classical & 57 & 22.0 & 0.72 & W151X/T93M & 0.30 \\
\hline 9 & 6 & Mild & 89 & 12 & 0.88 & IVS8-1G $>$ C/P51S & 0.35 \\
\hline $10^{\mathrm{b}}$ & 56 & Severe & 28 & 25.4 & 0.53 & IVS8-1G $>C / L 109 P$ & 0.23 \\
\hline $11^{\mathrm{b}}$ & 11 & Mild & 90 & 7.8 & 0.92 & IVS8-1G $>C / T 154 M$ & 0.50 \\
\hline 12 & 17 & Mild & 154 & 0.3 & 1.0 & IVS8-1G > C/S169L & 0.13 \\
\hline 13 & 17 & Mild & 76 & 9.4 & 0.89 & IVS8-1G > C/S169L & 0.41 \\
\hline 14 & 28 & Classical & 48 & 12 & 0.80 & IVS8-1G $>C / D 175 H$ & 0.32 \\
\hline 15 & 28 & Classical & 41 & 50 & 0.45 & IVS8-1G $>C / F 235 S$ & 0.25 \\
\hline $16^{\mathrm{b}}$ & 11 & Mild & 32 & 14 & 0.70 & IVS8-1G $>C / A 247 V$ & 0.65 \\
\hline 17 & 6 & Mild & 36 & 13 & 0.74 & IVS8-1G > C/A247V & 0.49 \\
\hline 18 & 56 & Severe & $\mathrm{N} / \mathrm{A}^{\mathrm{d}}$ & $\mathrm{N} / \mathrm{A}$ & $\mathrm{N} / \mathrm{A}$ & IVS8-1G $>C / W 248 R$ & 0.05 \\
\hline $19^{\mathrm{b}}$ & 6 & Mild & 89 & 5.2 & 0.93 & IVS8-1G > C/T289I & 0.49 \\
\hline $20^{\mathrm{b}}$ & 11 & Mild & 90 & 7.0 & 0.93 & IVS8-1G > C/T289I & 0.47 \\
\hline $21^{\mathrm{b}}$ & 17 & Mild & 70 & 14 & 0.83 & IVS8-1G $>C / Y 318 N$ & 0.08 \\
\hline 22 & 33 & Classical & 31 & 14 & 0.69 & IVS8-1G $>C / Y 318 N$ & 0.33 \\
\hline $23^{\mathrm{b}}$ & 28 & Classical & 15 & 8.3 & 0.64 & IVS8-1G $>$ C/L341P & 0.10 \\
\hline 24 & 22 & Classical & 79 & 14 & 0.85 & IVS8-1G $>C / R 352 W$ & 0.11 \\
\hline 25 & 39 & Severe & 35 & 47 & 0.43 & IVS8-1G >C/R352W & 0.18 \\
\hline 26 & 50 & Severe & 52 & 51 & 0.50 & IVS8-1G > C/C380R & 0.04 \\
\hline 27 & 11 & Mild & 72 & 8.5 & 0.89 & IVS8-1G $>C / C 380 Y$ & 0.38 \\
\hline 28 & 6 & Mild & 105 & 14 & 0.88 & IVS8-1G $>C / C 380 Y$ & 0.40 \\
\hline 29 & 44 & Severe & 9 & 12 & 0.43 & IVS8-1G $>C / R 404 C$ & 0.04 \\
\hline 30 & 70 & Severe & N/A & N/A & N/A & IVS8-1G $>C / R 404 C$ & 0.09 \\
\hline $31^{\mathrm{b}}$ & 45 & Severe & 50 & 17 & 0.75 & IVS8-1G >C/E448K & 0.10 \\
\hline 32 & 22 & Classical & 88 & 4.9 & 0.95 & P51S/ E448K & 0.34 \\
\hline $33^{\mathrm{c}}$ & 6 & Mild & 114 & 5.4 & 0.95 & Q98X/R450L & 0.33 \\
\hline $34^{\mathrm{b}}$ & 11 & Mild & 76 & 16 & 0.82 & $321 \mathrm{G}>\mathrm{C} / \mathrm{C} 444 \mathrm{Y}$ & 0.10 \\
\hline 35 & 70 & Severe & N/A & N/A & N/A & G138V/H405Y & 0.02 \\
\hline 36 & 17 & Mild & 65 & 13 & 0.83 & $\mathrm{I} 145 \mathrm{~L} / \mathrm{Y} 408 \mathrm{H}$ & 0.47 \\
\hline $37^{\mathrm{b}}$ & 55 & Severe & 8.3 & 8.6 & 0.49 & G147D/R242H & 0.11 \\
\hline 38 & 22 & Classical & 63 & 4.9 & 0.93 & $\mathrm{~T} 154 \mathrm{M} / \mathrm{R} 443 \mathrm{H}$ & 0.51 \\
\hline 39 & 11 & Mild & 131 & 2.0 & 0.98 & $\mathrm{R} 242 \mathrm{C} / \mathrm{S} 169 \mathrm{~L}$ & 0.58 \\
\hline 40 & 11 & Mild & 109 & 2.6 & 0.98 & R242C/R450L & 0.24 \\
\hline 41 & 11 & Mild & 83 & 3.4 & 0.96 & R242C/R450L & 0.19 \\
\hline 42 & 11 & Mild & 20 & 7.8 & 0.72 & $\mathrm{R} 242 \mathrm{C} / \mathrm{H} 426 \mathrm{P}$ & 0.25 \\
\hline 43 & 39 & Severe & 8 & 24 & 0.25 & R242C/G344R & 0.04 \\
\hline $44^{\mathrm{b}}$ & 17 & Mild & 94 & 4.2 & 0.96 & R242C/W177R & 0.48 \\
\hline 45 & 11 & Mild & 117 & 5.9 & 0.95 & C380Y/E448K & 0.37 \\
\hline 46 & 28 & Classical & 36 & 13 & 0.73 & G410S/G410S & 0.05 \\
\hline $47^{\mathrm{a}}$ & 60 & Severe & 33 & 31 & 0.52 & $\begin{array}{l}\mathrm{C} \text { insertion }(507 / 508) \\
96 \text { bp deletion }(-77 \text { to } 19)\end{array}$ & 0.07 \\
\hline 48 & 0 & Heterozygote & N/A & N/A & N/A & $+/ \mathrm{S} 113 \mathrm{C}$ & 0.85 \\
\hline 49 & 0 & Heterozygote & N/A & N/A & N/A & $+/$ IVS8-1G $>C$ & 0.85 \\
\hline 50 & 0 & Heterozygote & N/A & N/A & N/A & $+/$ IVS8-1G $>C$ & 0.84 \\
\hline 51 & 0 & Heterozygote & N/A & N/A & N/A & $+/ 1348$ delC & 0.92 \\
\hline 52 & 0 & Control & N/A & N/A & N/A & $+/+$ & 1.0 \\
\hline 53 & 0 & Control & N/A & N/A & N/A & $+/+$ & 1.0 \\
\hline 54 & 0 & Control & N/A & N/A & N/A & $+/+$ & 1.0 \\
\hline
\end{tabular}



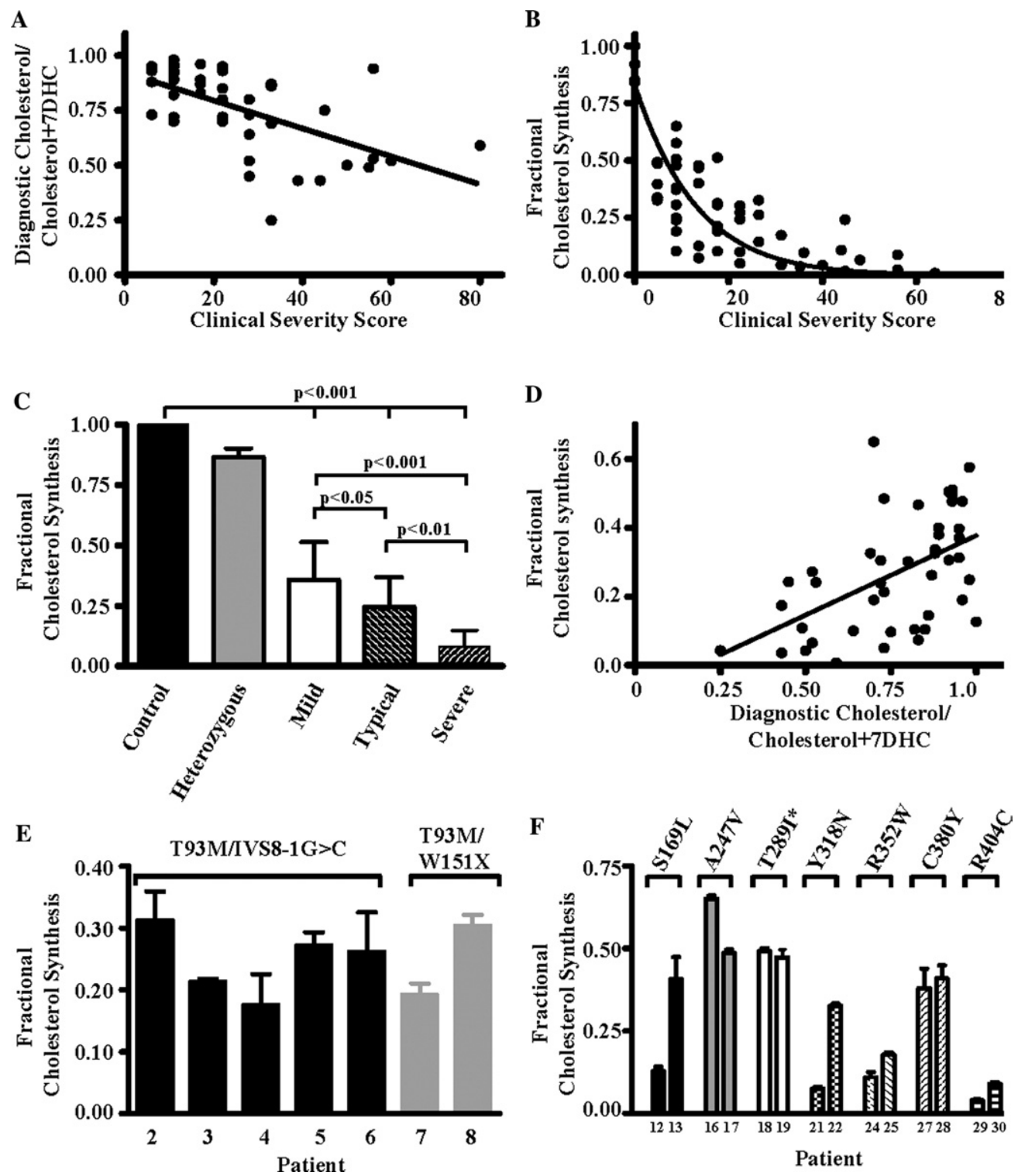

Fig. 2. Cholesterol synthesis in SLOS skin fibroblasts. (A) Increased clinical severity scores correlate $\left(r^{2}=0.36, p<0.001\right)$ with a decreased fraction of cholesterol at diagnosis in the cohort of patients reported in this study. (B) Decreased fractional cholesterol synthesis (cholesterol/ cholesterol + 7DHC) in SLOS fibroblasts correlate $\left(r^{2}=0.45, p<0.0001\right)$ with increased clinical severity scores. This relationship can be modeled by a Gaussian distribution (solid line). (C) Fractional cholesterol synthesis in control and heterozygous cell lines compared to SLOS patients separated into mild, typical and severe phenotypes. Significant differences are indicated. Error bars represent standard deviation. (D) The correlation between the fraction of cholesterol present in plasma at diagnosis and the fractional cholesterol synthesis determined in patient fibroblasts is shown. (E) Fractional cholesterol synthesis in skin fibroblasts from patients with T93M/IVS8-1G > C (black bars) or T93M/W151X (gray bars) genotypes. IVS8-1G $>\mathrm{C}$ and W151X are null mutations. Mean fractional cholesterol synthesis for $D H C R 7^{\mathrm{T} 93 \mathrm{M} / \text { null }}$ fibroblasts was $24 \pm 6 \%$. (F) Fractional cholesterol synthesis from patients with the same genotype. In all cases, the second allele is IVS8-1G $>$ C. *Patients 18 and 19 are siblings.

range is observed in each category, a significant linear trend $(p=0.03)$ of decreased fractional cholesterol synthesis with increasing mutational severity group was observed (Fig. 3). The large range of residual cholesterol synthesis observed for the TM category $(0.04-0.65)$ precludes its use as a predictive structural element. Other mutations clearly do not behave as predicted by this model. E448K is a CT mutation and predicted to be a mild mutation; however, in combination with IVS8$1 \mathrm{G}>\mathrm{C}, \mathrm{E} 448 \mathrm{~K}$ is associated with a severe phenotype (patient 31 and data not shown) and relatively low fractional cholesterol synthesis (Fig. 3, gray circle). This particular mutation falls in the sterol reductase family signature 2 motif and this residue is conserved as a negatively charged amino acid (aspartate or glutamate) in most family members (http://us.expasy.org/prosite/). $\mathrm{C} 380 \mathrm{Y}$ is a $4 \mathrm{~L}$ mutation predicted by this model to be relatively severe; however, in patients 27 and 28 the IVS8-1G $>$ C/C380Y genotype is associated with both a mild phenotype and relatively high residual DHCR7 


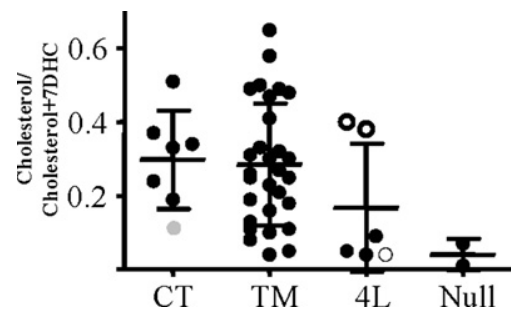

Fig. 3. Fractional cholesterol synthesis as a function of predicted mutation type. DHCR mutations have been classified into four groups of increasing severity based on predicted protein structure: carboxy terminus $(\mathrm{CT})<$ transmembrane $(\mathrm{TM})<$ fourth cytoplasmic loop $(4 \mathrm{~L})<$ null [44]. For this figure, patients were classified as to the least severe allele type. Insufficient patients were available to categorize patients with respect to both alleles. Individual values, mean, and standard deviation for each category are shown. Variation between means is not significant; however, there is a trend toward decreased fractional cholesterol synthesis with increased severity group $(p=0.03)$. Closed gray circle indicates IVS8-1G $>C$ /E448K genotype. Bold open circles indicate IVS8-1G $>\mathrm{C} / \mathrm{C} 380 \mathrm{Y}$ genotype and the light open circle indicates IVS8-1G $>$ C/C380R.

activity (Fig. 3, bold open circles). It is of interest to note that while $\mathrm{C} 380 \mathrm{Y}$ results in a mild phenotype with relatively high residual activity, C380R appears to cause a severe phenotype with significantly reduced residual cholesterol synthesis (Fig. 3, open circle). It is possible that the substitution of a charged amino acid in this position severely disrupts the function of this protein domain.

\section{Effect of simvastatin on residual cholesterol synthesis in SLOS fibroblasts}

Simvastatin use in SLOS patients has resulted in a paradoxical increase in serum and cerebral spinal fluid cholesterol levels [40]. It has been postulated that simvastatin, an HMG-CoA reductase inhibitor, may increase DHCR 7 activity by increasing $D H C R 7$ expression. We tested the effects of simvastatin on both $D H C R 7$ expression and fractional cholesterol synthesis in fibroblasts. Treatment of fibroblasts with simvastatin significantly increased $D H C R 7$ expression in both control and SLOS cell lines (Fig. 4A). A simvastatin induced increase in DHCR7 expression was observed when cells were cultured in either cholesterol containing or cholesterol-deficient medium. Simvastatin also increased expression of other SREBP2 regulated genes involved in cholesterol synthesis and uptake in both control and SLOS fibroblasts. These include HMG-CoA reductase $(H M G R)$, the low-density lipoprotein receptor $(L D L R)$, squalene synthase $(F D F T), \quad 3 \beta$-hydroxysterol $\Delta^{24}$-reductase (DHCR24), and NAD(P)H dependent steroid dehydrogenase-like $(N S D H L)$ (Figs. $4 \mathrm{~B}$ and $\mathrm{C}$, and data not shown).

We determined the effect of simvastatin on residual cholesterol synthesis in SLOS fibroblasts. Initial experi-
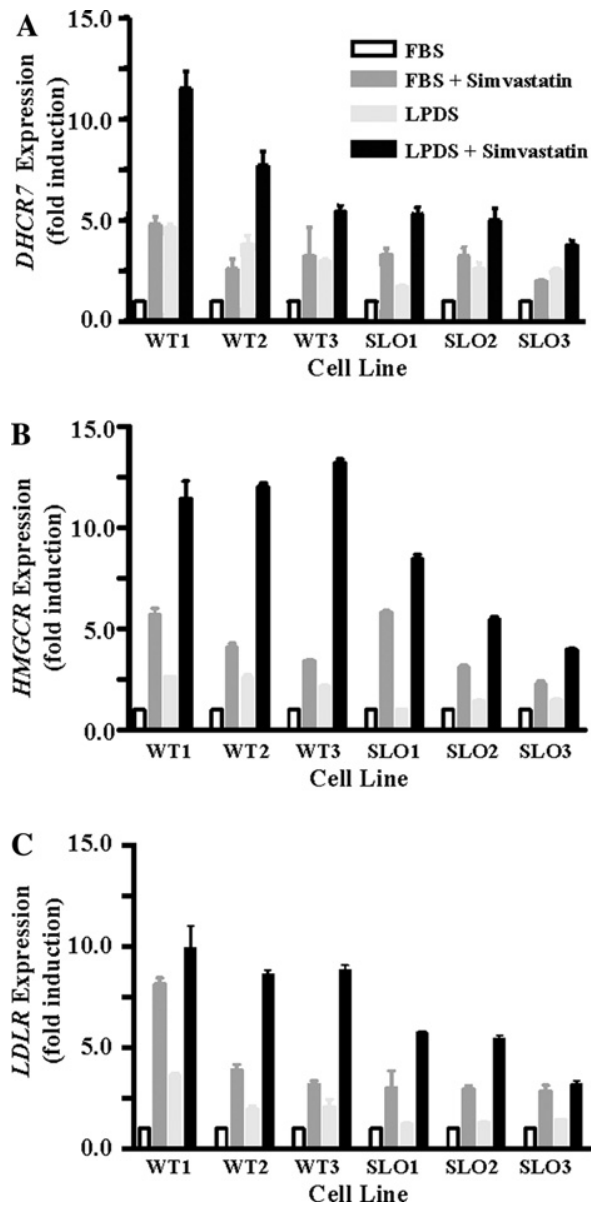

Fig. 4. Simvastatin induction of $D H C R 7$ expression. (A) Simvastatin $(5 \mathrm{mcg} / \mathrm{ml}$ ) significantly increased $D H C R 7$ expression in both control and SLOS fibroblasts. Increased expression occurred in both cholesterol containing medium (FBS) and cholesterol-deficient medium (LPDS). Similarly, simvastatin also induced expression of both $H M G C R$ (B) and LDLR (C) in both control and SLOS fibroblasts. Expression levels were normalized for each cell line to the gene expression level found in non-treated cells grown in cholesterol containing medium. Each determination is the average of 6-9 replicate cultures for $D H C R 7$, and 4-6 replicate cultures for both $H M G C R$ and $L D L R$. Error bars indicate standard deviation.

ments were performed using fibroblasts from patient number 2 (IVS8-1G $>$ C/T93M). Fig. 5A shows a dose dependent increase in fractional cholesterol synthesis in response to simvastatin treatment. Maximal residual cholesterol synthesis was observed using $2.5-5.0 \mathrm{mcg} /$ $\mathrm{ml}$ of simvastatin. A similar experiment was attempted in fibroblast lines with two null alleles (IVS8-1G $>\mathrm{C}$ / IVS8-1G $>C$ and IVS8-1G $>C$ /W151X). Simvastatin was toxic in these cell lines as evidenced by rapid cell death (data not shown). We also studied the ability of simvastatin to facilitate the removal of 7DHC. For these experiments, fibroblasts were grown in LPDS supplemented medium for 3 days and allowed to accumulate 7DHC. After 3 days, the cultures were either treated or not treated with $1.0 \mathrm{mcg} / \mathrm{ml}$ of simvastatin. Sterol 

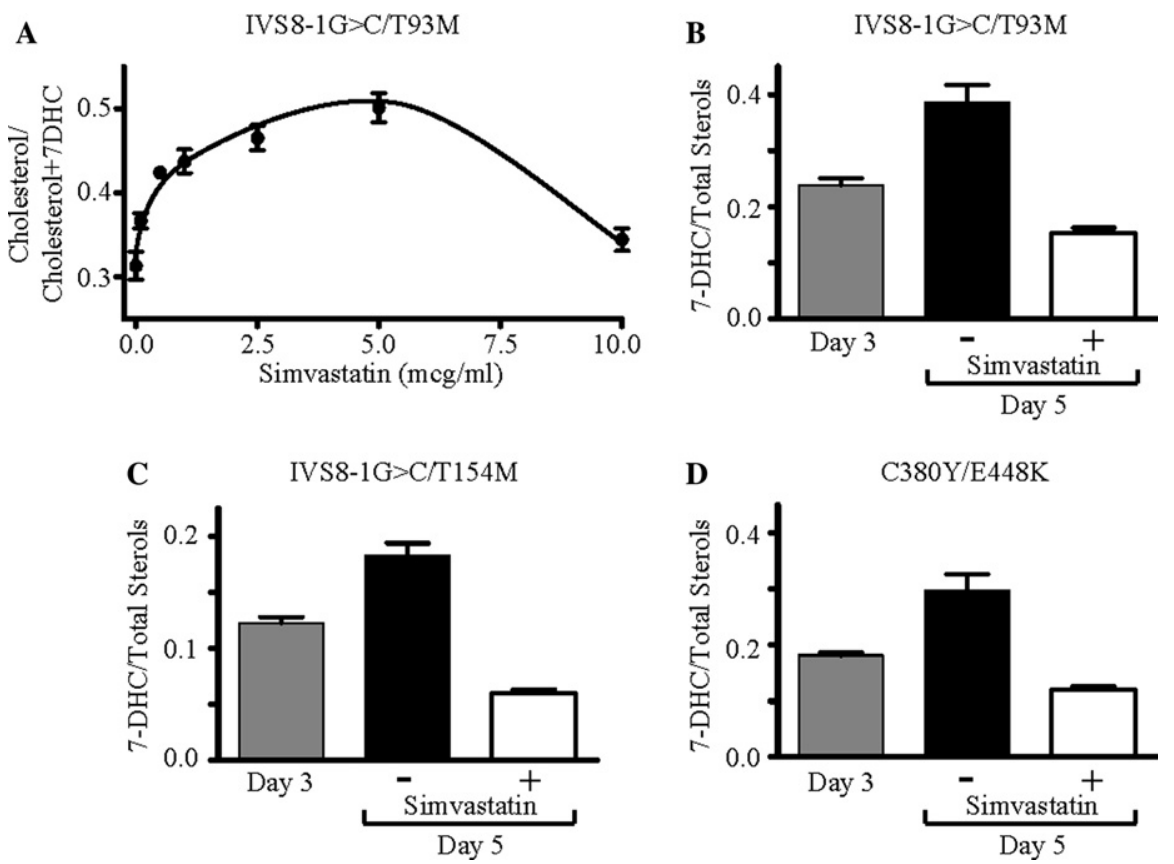

Fig. 5. Simvastatin induction of cholesterol synthesis in SLOS fibroblasts. (A) A dose dependent increase in fractional cholesterol synthesis was observed in an IVS8-1G > C/T93M SLOS cell line treated with simvastatin up to $5 \mathrm{mcg} / \mathrm{ml}$. This increase in fractional cholesterol synthesis was lost when cells were treated with $10 \mathrm{mcg} / \mathrm{ml}$ simvastatin. (B) IVS8-1G $>$ C/T93M fibroblasts were grown for three days in LPDS supplemented medium. The expected accumulation of 7DHC at this time point is indicated by the gray bar. On day three, parallel cultures were treated or not treated with $1 \mathrm{mcg} / \mathrm{ml}$ of simvastatin. After five days of culture, the fraction of 7DHC continued to increase in untreated cells (black bar) but decreased in simvastatin treated cell (open bar). Similar results were observed for both IVS8-1G > C/T154M (C) and C380Y/E448K (D) cell lines.

composition was determined 2 days later on experimental day five. Untreated IVS8-1G $>$ C/T93M cultures continued to accumulate 7DHC; whereas, the 7DHC fraction in simvastatin treated cultures was reduced (Fig. 5B). Similar results were obtained for fibroblasts from patient 11 (IVS8-1G $>$ C/T154M, Fig. 5C), and patient 45 (C380Y/E448K, Fig. 5D).

\section{Discussion}

SLOS is the prototypical example of a human malformation syndrome due to an inborn error of cholesterol synthesis, and represents the first classical human multiple malformation syndrome shown to have a biochemical cause. Establishing a genotype-phenotype correlation to explain the diverse clinical spectrum found in SLOS has been complicated by a number of factors. First, over 100 different DHCR7 mutations have been identified in SLOS patients [7], and the most common mutation (IVS8-1G $>$ C) only accounts for approximately a third of the identified alleles. Thus, most patients are compound heterozygote and few patients have the same genotype. Second, even patients with the same genotype can have markedly discordant phenotypes $[12,15]$. To gain insight into the influence of cellular cholesterol synthesis on the SLOS pheno- type, we measured residual cholesterol synthesis in skin fibroblasts from SLOS patients with known genotype and phenotype.

Sterol synthesis in SLOS fibroblasts was evaluated using mass isotopomer distribution analysis to measure deuterium incorporation into both cholesterol and 7DHC. Use of deuterium labeling is a well-established, non-radioactive technique to study cholesterol synthesis [17-22]. The DHCR7 genotype and residual cholesterol synthesis was determined for all fibroblast cell lines used in this study. For this population of SLOS patients, fractional cholesterol synthesis correlates with clinical severity and is well modeled by a Gaussian distribution (Fig. 2B). If the assumption that cholesterol synthesis in skin fibroblasts reflects cholesterol synthesis in embryonic tissues is accepted, then the results in this study argue that clinical severity is related to the amount of residual DHCR7 activity present. This is expected. However, at the individual level we still find a significant amount of variation in fractional cholesterol synthesis for patients with the same clinical severity score. Some of this variation may be due to differences in determination of residual cholesterol synthesis as measured in skin fibroblasts, and residual cholesterol synthesis present in different cell types during embryonic development. Some of this variation may be due to limitations of the severity score. The severity score, 
initially developed by Bialer et al. [48] to separate type I and type II SLOS, was subsequently modified by Kelly and Hennekam [11] to evaluate severity of physical malformations. With continued expansion of the SLOS phenotypic spectrum, limitations of this scoring system to differentiate among cases have become apparent. Although, in general, cell lines from patients with the same genotype had similar fractional cholesterol synthesis, we observed approximately a twofold range $(0.16-0.31)$ in fibroblasts from null/T93M patients. This result suggests that some of the clinical variation in SLOS may be due to factors, other than DHCR7 genotype, that influence cholesterol synthesis and homeostasis at the cellular level. Clinical variability is also influenced by maternal factors that would not be a factor in these in vitro experiments. WitschBaumgartner et al. [16] have reported that maternal, but not patient, apoE genotype is significantly correlated with phenotypic severity.

Dietary cholesterol supplementation has become the standard therapy for SLOS; however, it has several limitations including inability to treat the central nervous system. Because of these limitations, use of simvastatin in SLOS has been proposed [39-41]. Simvastatin is an inhibitor of 3-hydroxy-3 methylglutaryl-coenzyme A reductase (HMG-CoA reductase, HMGCR). HMGCoA reductase catalyzes the conversion of HMG-CoA to mevalonate and is the rate-limiting step in cholesterol biosynthesis. Simvastatin crosses the blood-brain barrier [49], thus simvastatin therapy may provide a means to treat the biochemical defect present in the central nervous system of SLOS patients.

With prolonged simvastatin therapy, Jira et al. [40] reported decreased serum dehydrocholesterol levels and increased plasma cholesterol levels. Consistent with distribution into the central nervous system, this group also reported an improved $7 \mathrm{DHC} /$ cholesterol ratio in cerebral spinal fluid. It is hypothesized that the paradoxical increase in plasma cholesterol levels results from increased expression of a mutant enzyme with residual DHCR 7 activity.

The data presented in this manuscript support this hypothesis. Specifically, we showed that simvastatin increases DHCR7 expression and increases residual cholesterol synthesis in SLOS fibroblasts. Quantitative PCR analysis showed that simvastatin treatment significantly increases the expression of $D H C R 7$ in both control and SLOS fibroblasts (Fig. 4A). Increased expression of $D H C R 7$ is likely mediated by SREBP2. In HepG2 cells, HMG-CoA reductase inhibitors increase levels of activated SREBP2 in nuclear extracts [50], and SREBP2 has been shown to regulate $D H C R 7$ expression [51,52]. Consistent with an SREBP2 mediated process, we observed increased expression of $L D L R, H M G C R, F D F T, D H C R 24$, and NSDHL in both control and SLOS fibroblasts treated with simva- statin. Expression of this group of genes is regulated by SREBP2 [52,53].

We also analyzed the biochemical effects of simvastatin treatment of SLOS fibroblasts. A dose dependent increase in fractional cholesterol synthesis that peaked at $5 \mathrm{mcg} / \mathrm{ml}$ was observed (Fig. 5A), and simvastatin treatment reduced 7DHC levels in SLOS fibroblasts (Figs. 5B and C). These results are consistent with the hypothesis that increased expression of a hypomorphic $\mathrm{DHCR} 7$ allele results in increased conversion of 7DHC to cholesterol, and is a potential explanation of the paradoxical increase in serum cholesterol reported by Jira et al. [40].

If the benefits of simvastatin therapy in SLOS were due to increased expression of an allele with residual DHCR 7 activity, then one would predict that simvastatin would not be beneficial in severely affected patients with low residual DHCR7 enzymatic activity. Starck [41] reported clinical problems in two SLOS patients treated with simvastatin. These authors questioned the safety of simvastatin in severely affected SLOS patients and the usefulness of the clinical severity score as a method to predict patients who might have an adverse reaction to simvastatin therapy. One of these patients was reported to have less than $5 \%$ DHCR7 activity [54]. This is supported by our observation of increased toxicity of simvastatin in cell lines with two null DHCR7 alleles.

A major issue confronting the treatment of SLOS patients is whether the mental and behavioral problems represent fixed developmental problems or a consequence of disturbed CNS function due to the presence of abnormal sterols. In the latter case, therapeutic interventions that improve CNS sterol composition may have beneficial effects. Larger, controlled, and blinded studies are needed to evaluate both the safety and efficacy of simvastatin therapy in SLOS patients. The methods and data presented in this paper can be used to help identify patients who may benefit from simvastatin therapy, and similarly identify patients for whom simvastatin may be detrimental. Caution should be used in treating patients with low residual DHCR7 activity or a DHCR7 genotype associated with low activity until more information on mechanism, safety, and efficacy is available.

\section{Acknowledgments}

The authors acknowledge specifically the contributions of our patient's families and the Smith-LemliOpitz/RSH Syndrome Network in general to this work. The authors would also like to acknowledge the generous contribution of cell lines from various physicians including Robert D. Steiner and Richard I. Kelley and assistance from Lina S. Correa-Cerro. We appreciate the generous gift of simvastatin from Merck and Com- 
pany. We would finally like to express our gratitude to the parents of our patients for their willing participation in our SLOS clinical protocols.

\section{References}

[1] M. Irons, E.R. Elias, G. Salen, G.S. Tint, A.K. Batta, Defective cholesterol biosynthesis in Smith-Lemli-Opitz syndrome, Lancet 341 (1993) 1414.

[2] G.S. Tint, M. Irons, E.R. Elias, A.K. Batta, R. Frieden, T.S. Chen, G. Salen, Defective cholesterol biosynthesis associated with the Smith-Lemli-Opitz syndrome, N. Engl. J. Med. 330 (1994) $107-113$.

[3] B.U. Fitzky, M. Witsch-Baumgartner, M. Erdel, J.N. Lee, Y.K. Paik, H. Glossmann, G. Utermann, F.F. Moebius, Mutations in the Delta7-sterol reductase gene in patients with the SmithLemli-Opitz syndrome, Proc. Natl. Acad. Sci. USA 95 (1998) 8181-8186.

[4] F.F. Moebius, B.U. Fitzky, J.N. Lee, Y.-K. Paik, H. Glossmann, Molecular cloning and expression of the human delta 7-sterol reductase, Proc. Natl. Acad. Sci. USA 95 (1998) 1899-1902.

[5] C.A. Wassif, C. Maslen, S. Kachilele-Linjewile, D. Lin, L.M. Linck, W.E. Connor, R.D. Steiner, F.D. Porter, Mutations in the human sterol delta7-reductase gene at 11q12-13 cause SmithLemli-Opitz syndrome, Am. J. Hum. Genet. 63 (1998) 55-62.

[6] H.R. Waterham, F.A. Wijburg, R.C.M. Hennekam, P. Vreken, B.T. Poll-The, L. Dorland, M. Duran, P.E. Jira, J.A.M. Smeitink, R.A. Wevers, R.J.A. Wanders, Smith-Lemli-Opitz syndrome is caused by mutations in the 7-dehydrocholesterol reductase gene, Am. J. Hum. Genet. 63 (1998) 329-338.

[7] L.S. Correa-Cerro, F.D. Porter, $3 \beta$-Hydroxysterol $\Delta^{7}$-reductase and the Smith-Lemli-Opitz syndrome, Mol. Genet. Metab. 84 (2005) 112-126.

[8] R.I. Kelley, G.E. Herman, Inborn errors of sterol biosynthesis, Annu. Rev. Genom. Hum. Genet. 2 (2001) 299-341.

[9] M.J. Nowaczyk, D. McCaughey, D.T. Whelan, F.D. Porter, Incidence of Smith-Lemli-Opitz syndrome in Ontario, Canada, Am. J. Med. Genet. 102 (2001) 18-20.

[10] A.K. Ryan, K. Bartlett, P. Clayton, S. Eaton, L. Mills, D. Donnai, R.M. Winter, J. Burn, Smith-Lemli-Opitz syndrome: a variable clinical and biochemical phenotype, J. Med. Genet. 35 (1998) 558-565.

[11] R.I. Kelley, R.C. Hennekam, The Smith-Lemli-Opitz syndrome, J. Med. Genet. 37 (2000) 321-335.

[12] F.D. Porter, RSH/Smith-Lemli-Opitz syndrome: a multiple congenital anomaly/mental retardation syndrome due to an inborn error of cholesterol biosynthesis, Mol. Genet. Metab. 71 (2000) 163-174

[13] J.M. Opitz, E. Gilbert-Barness, J. Ackerman, A. Lowichik, Cholesterol and development: the RSH ("Smith-Lemli-Opitz") syndrome and related conditions, Pediatr. Pathol. Mol. Med. 21 (2002) 153-181.

[14] E. Tierney, N.A. Nwokoro, F.D. Porter, L.S. Freund, J.K. Ghuman, R.I. Kelley, Behavior phenotype in the RSH/SmithLemli-Opitz syndrome, Am. J. Med. Genet. 98 (2001) 191200.

[15] L.S. Correa-Cerro, C.A. Wassif, J.S. Waye, P.A. Krakowiak, D. Cozma, N.R. Dobson, S.W. Levin, G. Anadiotis, R.D. Steiner, M. Krajewska-Walasek, M.J. Nowaczyk, F.D. Porter, DHCR7 nonsense mutations and characterization of mRNA nonsense mediated decay in Smith-Lemli-Opitz syndrome, J. Med. Genet. (2005) in press.

[16] M. Witsch-Baumgartner, M. Gruber, H.G. Kraft, M. Rossi, P. Clayton, M. Giros, D. Haas, R.I. Kelley, M. Krajewska-Walasek, G. Utermann, Maternal apo E genotype is a modifier of the
Smith-Lemli-Opitz syndrome, J. Med. Genet. 41 (2004) 577584.

[17] N.B. Javitt, J.I. Javitt, Cholesterol and bile acid synthesis: utilization of $\mathrm{D}_{2} \mathrm{O}$ for metabolic studies, Biomed. Environ. Mass Spectrom. 18 (1989) 624-628.

[18] M. Di Buono, P.J. Jones, L. Beaumier, L.J. Wykes, Comparison of deuterium incorporation and mass isotopomer distribution analysis for measurement of human cholesterol biosynthesis, J. Lipid Res. 41 (2000) 1516-1523.

[19] W.N. Lee, S. Bassilian, H.O. Ajie, D.A. Schoeller, J. Edmond, E.A. Bergner, L.O. Byerley, In vivo measurement of fatty acids and cholesterol synthesis using $\mathrm{D}_{2} \mathrm{O}$ and mass isotopomer analysis, Am. J. Physiol. 266 (1994) E699-E708.

[20] W.N. Lee, S. Bassilian, Z. Guo, D. Schoeller, J. Edmond, E.A. Bergner, L.O. Byerley, Measurement of fractional lipid synthesis using deuterated water $\left(2 \mathrm{H}_{2} \mathrm{O}\right)$ and mass isotopomer analysis, Am. J. Physiol. 266 (1994) E372-E383.

[21] F. Diraison, C. Pachiaudi, M. Beylot, In vivo measurement of plasma cholesterol and fatty acid synthesis with deuterated water: determination of the average number of deuterium atoms incorporated, Metabolism 45 (1996) 817-821.

[22] M.R. Lakshmanan, R.L. Veech, Measurement of rate of rat liver sterol synthesis in vivo using tritiated water, J. Biol. Chem. 252 (1977) 4667-4673.

[23] E.R. Elias, M.B. Irons, A.D. Hurley, G.S. Tint, G. Salen, Clinical effects of cholesterol supplementation in six patients with the Smith-Lemli-Opitz syndrome (SLOS) [see comments], Am. J. Med. Genet. 68 (1997) 305-310.

[24] M. Irons, E.R. Elias, D. Abuelo, M.J. Bull, C.L. Greene, V.P. Johnson, L. Keppen, C. Schanen, G.S. Tint, G. Salen, Treatment of Smith-Lemli-Opitz syndrome: results of a multicenter trial, Am. J. Med. Genet. 68 (1997) 311-314.

[25] N.A. Nwokoro, J.J. Mulvihill, Cholesterol and bile acid replacement therapy in children and adults with Smith-LemliOpitz (SLO/RSH) syndrome, Am. J. Med. Genet. 68 (1997) 315321.

[26] R.I. Kelley, Inborn errors of cholesterol biosynthesis, Adv. Pediatr. 47 (2000) 1-53.

[27] A. Martin, K. Koenig, L. Scahill, E. Tierney, F.D. Porter, N.A. Nwokoro, Smith-Lemli-Opitz syndrome, J. Am. Acad. Child Adolesc. Psychiatry 40 (2001) 506-507.

[28] S.D. Turley, D.K. Burns, C.R. Rosenfeld, J.M. Dietschy, Brain does not utilize low density lipoprotein-cholesterol during fetal and neonatal development in the sheep, J. Lipid Res. 37 (1996) 1953-1961.

[29] S.D. Turley, D.K. Burns, J.M. Dietschy, Preferential utilization of newly synthesized cholesterol for brain growth in neonatal lambs, Am. J. Physiol. 274 (1998) E1099-E1105.

[30] H.A. Jurevics, F.Z. Kidwai, P. Morell, Sources of cholesterol during development of the rat fetus and fetal organs, J. Lipid Res. 38 (1997) 723-733.

[31] H. Jurevics, P. Morell, Cholesterol for synthesis of myelin is made locally, not imported into brain, J. Neurochem. 64 (1995) 895 901.

[32] W.M. Pardridge, L.J. Mietus, Palmitate and cholesterol transport through the blood-brain barrier, J. Neurochem. 34 (1980) 463 466.

[33] C.A. Wassif, D. Vied, M. Tsokos, W.E. Connor, R.D. Steiner, F.D. Porter, Cholesterol storage defect in RSH/Smith-LemliOpitz syndrome fibroblasts, Mol. Genet. Metab. 75 (2002) 325-334.

[34] B.U. Fitzky, F.F. Moebius, H. Asaoka, H. Waage-Baudet, L. Xu, G. Xu, N. Maeda, K. Kluckman, S. Hiller, H. Yu, A.K. Batta, S. Shefer, T. Chen, G. Salen, K. Sulik, R.D. Simoni, G.C. Ness, H. Glossmann, S.B. Patel, G.S. Tint, 7-Dehydrocholesterol-dependent proteolysis of HMG-CoA reductase suppresses sterol biosynthesis in a mouse model of Smith-LemliOpitz/RSH syndrome, J. Clin. Invest. 108 (2001) 905-915. 
[35] C.A. Wassif, J. Yu, J. Cui, F.D. Porter, N.B. Javitt, 27Hydroxylation of 7- and 8-dehydrocholesterol in Smith-LemliOpitz syndrome: a novel metabolic pathway, Steroids 68 (2003) 497-502.

[36] M.R. Natowicz, J.E. Evans, Abnormal bile acids in the SmithLemli-Opitz syndrome, Am. J. Med. Genet. 50 (1994) 364-367.

[37] A. Honda, G. Salen, S. Shefer, A.K. Batta, M. Honda, G. Xu, G.S. Tint, Y. Matsuzaki, J. Shoda, N. Tanaka, Bile acid synthesis in the Smith-Lemli-Opitz syndrome: effects of dehydrocholesterols on cholesterol 7alpha-hydroxylase and 27-hydroxylase activities in rat liver, J. Lipid Res. 40 (1999) 1520-1528.

[38] C.H. Shackleton, E. Roitman, L.-W. Guo, W.K. Wilson, F.D. Porter, Identification of 7(8) and 8(9) unsaturated adrenal steroid metabolites produced by patients with 7-dehydrocholesteroldelta7-reductase deficiency (Smith-Lemli-Opitz syndrome), J. Steroid Biochem. Mol. Biol. 82 (2002) 225-232.

[39] P. Jira, R. Wevers, J. de Jong, E. Rubio-Gozalbo, J. Smeitink, New treatment strategy for Smith-Lemli-Opitz syndrome, Lancet 349 (1997) 1222.

[40] P.E. Jira, R.A. Wevers, J. de Jong, E. Rubio-Gozalbo, F.S. Janssen-Zijlstra, A.F. van Heyst, R.C. Sengers, J.A. Smeitink, Simvastatin. A new therapeutic approach for Smith-Lemli-Opitz syndrome, J. Lipid Res. 41 (2000) 1339-1346.

[41] L. Starck, A. Lovgren-Sandblom, I. Bjorkhem, Simvastatin treatment in the SLO syndrome: a safe approach?, Am. J. Med. Genet. 113 (2002) 183-189.

[42] L.E. Kratz, R.I. Kelley, Prenatal diagnosis of the RSH/SmithLemli-Opitz syndrome, Am. J. Med. Genet. 82 (1999) 376-381.

[43] P.A. Krakowiak, N.A. Nwokoro, C.A. Wassif, K.P. Battaile, M.J. Nowaczyk, W.E. Connor, C. Maslen, R.D. Steiner, F.D. Porter, Mutation analysis and description of sixteen RSH/Smith-LemliOpitz syndrome patients: polymerase chain reaction-based assays to simplify genotyping, Am. J. Med. Genet. 94 (2000) 214-227.

[44] M. Witsch-Baumgartner, B.U. Fitzky, M. Ogorelkova, H.G. Kraft, F.F. Moebius, H. Glossmann, U. Seedorf, G. GillessenKaesbach, G.F. Hoffmann, P. Clayton, R.I. Kelley, G. Utermann, Mutational spectrum in the Delta7-sterol reductase gene and genotype-phenotype correlation in 84 patients with Smith-LemliOpitz syndrome, Am. J. Hum. Genet. 66 (2000) 402-412.
[45] B.E. Cham, B.R. Knowles, A solvent system for delipidation of plasma or serum without protein precipitation, J. Lipid Res. 17 (1976) 176-181.

[46] R.I. Kelley, Diagnosis of Smith-Lemli-Opitz syndrome by gas chromatography/mass spectrometry of 7-dehydrocholesterol in plasma, amniotic fluid and cultured skin fibroblasts, Clin. Chim. Acta 236 (1995) 45-58.

[47] H. Yu, M.H. Lee, L. Starck, E.R. Elias, M. Irons, G. Salen, S.B. Patel, G.S. Tint, Spectrum of Delta(7)-dehydrocholesterol reductase mutations in patients with the Smith-Lemli-Opitz (RSH) syndrome, Hum. Mol. Genet. 9 (2000) 1385-1391.

[48] M.G. Bialer, V.B. Penchaszadeh, E. Kahn, R. Libes, G. Krigsman, M.L. Lesser, Female external genitalia and mullerian duct derivatives in a 46,XY infant with the Smith-Lemli-Opitz syndrome, Am. J. Med. Genet. 28 (1987) 723-731.

[49] A. Saheki, T. Terasaki, I. Tamai, A. Tsuji, In vivo and in vitro blood-brain barrier transport of 3-hydroxy-3-methylglutaryl coenzyme A (HMG-CoA) reductase inhibitors, Pharm. Res. 11 (1994) 305-311.

[50] H. Scharnagl, R. Schinker, H. Gierens, M. Nauck, H. Wieland, W. Marz, Effect of atorvastatin, simvastatin, and lovastatin on the metabolism of cholesterol and triacylglycerides in HepG2 cells, Biochem. Pharmacol. 62 (2001) 1545-1555.

[51] J.H. Kim, J.N. Lee, Y.K. Paik, Cholesterol biosynthesis from lanosterol. A concerted role for Spl and NF-Y-binding sites for sterol-mediated regulation of rat 7-dehydrocholesterol reductase gene expression, J. Biol. Chem. 276 (2001) 18153-18160.

[52] J.D. Horton, N.A. Shah, J.A. Warrington, N.N. Anderson, S.W. Park, M.S. Brown, J.L. Goldstein, Combined analysis of oligonucleotide microarray data from transgenic and knockout mice identifies direct SREBP target genes, Proc. Natl. Acad. Sci. USA 100 (2003) 12027-12032.

[53] J.D. Horton, J.L. Goldstein, M.S. Brown, SREBPs: transcriptional mediators of lipid homeostasis, Cold Spring Harb. Symp. Quant. Biol. 67 (2002) 491-498.

[54] E. Lund, L. Starck, N. Venizelos, Detection of defective 3 betahydroxysterol delta 7-reductase activity in cultured human fibroblasts: a method for the diagnosis of Smith-Lemli-Opitz syndrome, J. Inherit. Metab. Dis. 19 (1996) 59-64. 